\title{
THE INFLUENCES OF THE SOUTH-TO-NORTH WATER TRANSFER PROJECT ON NITROGEN REMOVAL BY SOIL IN A TERMINAL RESERVOIR IN A CRITICAL STATE IN CHINA
}

\author{
XUE, W.L. ${ }^{1,2}-$ LI, F.H. ${ }^{1 *}-$ ZHAO, H.G. ${ }^{3 *}$ \\ ${ }^{1}$ College of Water Resources and Civil Engineering, China Agricultural University, Beijing \\ 10083, PR China \\ ${ }^{2}$ Beijing Water Science and Technology Institute, Beijing 100048, PR China \\ ${ }^{3}$ Institute of Environment and Sustainable Development in Agriculture, Chinese Academy of \\ Agricultural Sciences, Beijing 100081, PR China \\ *Corresponding authors \\ e-mail: lifahu@cau.edu.cn,zhaohaigen@caas.cn; phone/fax: +86-010-6273-7706/7796 (F. Li), \\ +86-010-8210-6007/9567 (H. Zhao) \\ (Received 25 $5^{\text {th }}$ Jun 2019; accepted $15^{\text {th }}$ Nov 2019)
}

\begin{abstract}
Soil in riparian zone can alleviate the risk of nitrogen pollution for water by releasing gaseous nitrogen $(\mathrm{N})$ fluxes. As a critically terminal riparian zone in China, the Miyun Reservoir riparian zone is dramatically submerged by water delivered by the South-to-North Water Transfer Project (SNWTP), which is the largest inter-basin water transfer scheme worldwide. However, few studies have proposed a framework to estimate the effect of SNWTP on N removal by soil at the scale of the riparian catchment. Therefore, a framework that integrates the eco-hydrological model, remote sensing technology, and scenario setting was developed in this study to simulate the spatiotemporal variation of $\mathrm{N}$ emissions and to estimate the influences of SNWTP on N removal by soil in the Miyun riparian catchment between April and September of 2015. The simulated results indicate that $\mathrm{N}$ removal in the whole catchment ranged from $48.83 \mathrm{t}$ to $290.58 \mathrm{t}$ between April and September and the total $\mathrm{N}$ removal was $871.97 \mathrm{t}$ in 2015. With water level exceeding $150 \mathrm{~m}$ and $160 \mathrm{~m}$, the riparian soil had about $35 \%-60 \%$ of its original $\mathrm{N}$ pollution mitigation ability. Changing farmland and grassland into forestland can effectively offset the impacts of SNWTP.
\end{abstract}

Keywords: nitrogen pollution, eco-hydrological model, riparian zone, scenario setting, remote sensing, Miyun reservoir

\section{Introduction}

To relieve the emerging crises of water resource shortage, inter-basin water transfer projects are beginning to be used throughout the world. Prominent examples are the Snowy Mountains Scheme in Australia, the California State Water Project in the United States, the West-to-East Water Transfer Project in Pakistan, the Quebec Water Transfer Project in Canada, the Lesotho Highlands Water Project in Lesotho and South Africa, and the Durance-Verdun Water Transfer Project in France (Chen et al., 2013; Wang et al., 2009; Yang et al., 2018a).

A complete water transfer project needs to draw water from a water source, transport this water via conveyance canals, and inject the water into the terminal reservoir (Yang et al., 2018a). Each part of such a water diversion causes different ecological and environmental problems. Specifically, the supply of adequate water without pollution is the most important item to be considered for the water source region ( $\mathrm{Gu}$ et al., 2012; Tang et al., 2014; Yang et al., 2016; Zhang, 2009; Zeng et al., 2015); the maintenance of 
adequate water quality and the prevention of disease spread should be the greatest concern in the conveyance canal (Yang et al., 2018a); for the terminal reservoir, protection functions of riparian areas is the main issue due to the drastic increase of the reservoir water level induced by the injection of transferred water (Zhang, 2009; Zhuang, 2016).

So far, the South-to-North Water Transfer Project (SNWTP) that was started to be built in China in 2002 is the largest inter-basin water transfer scheme in the world (Barnett et al., 2015; Li et al., 2016). It includes three independent routines, namely, west, east, and middle routes, where the last two routes have been completed and can deliver about 25 billion $\mathrm{m} 3$ of water per year (Liu and Zheng, 2002). At present, a number of studies have reported the ecological and environmental issues related to the SNWTP (Gu et al., 2012; Li et al., 2017; Ma et al., 2014; Tang et al., 2014; Yang et al., 2016, 2012; Zhang et al., 2008, 2018). However, most of these studies focused the water source region and on conveyance canals, while studies on effects of SNWTP on the terminal reservoir are rare.

The riparian zone is the transition region between water and terrace (King et al., 2016). It can intercept non-point source (NPS) pollutants from upland and therefore plays an important role in reducing the pollution risk of the water resource (de Sosa et al., 2018; Shu et al., 2017; Wei et al., 2017). In recent years, NPS N is becoming the key pollutant endangering the water quality safety in the world (Blackburn et al., 2017; Erisman et al., 2013). A number of studies have proposed that the soil in the riparian zone can effectively remove $\mathrm{N}$ pollution by releasing gaseous $\mathrm{N}$ fluxes (Butterbach-Bahl et al., 2013; de Sosa et al., 2018; Jacinthe and Vidon, 2017; Seitzinger et al., 2006). Furthermore, denitrification, nitrification, and ammonium volatilization have been reported as the three main biochemical processes related to the soil N emission (de Sosa et al., 2018; Groffman et al., 2009; Vymazal, 2007; Wang et al., 2010). In addition, various factors such as soil contents of organic carbon and inorganic nitrogen, moisture, temperature, $\mathrm{PH}$, and microbial activity exert important impacts on soil gaseous $\mathrm{N}$ emission fluxes (Brovelli et al., 2012; de Sosa et al., 2018; Figueiredo et al., 2016; Rojas-Oropeza et al., 2010; Si et al., 2018; Wang et al., 2010).

In the past studies, a combination of field sampling and mathematical statistics was usually employed to explore the variance of soil $\mathrm{N}$ in the riparian zone (Lind et al., 2013; Shu et al., 2017; de Sosa et al., 2018; Ye et al., 2014; Zhong et al., 2018). This type of method is easy to be conducted; however, it is very difficult to adequately yield an explanation of mechanistic processes and to operate it at the catchment scale (Hoang et al., 2017). In addition, a number of specifically processed models have been developed to simulate the hydrological processes and $\mathrm{N}$ dynamics in the riparian, such as the Riparian Soil Model (Brovelli et al., 2012), Wetlands Water Quality Model (Chavan and Dennett, 2008), Soil and Water Assessment Tool-Riparian Ecosystem Management Model (SWAT-REMM, Ryu et al., 2011), Penn State Integrated Hydrological Wetland Model (Zhang et al., 2018), and modified SWAT (SWT-LS, Hoang et al., 2017). In recent years, with the development of remote sensing technology, satellite images with high temporal and spatial resolutions can display the variance of land cover for a large-scale region (Islam and Sado, 2000; Zhao et al., 2018). Moreover, N emissions by the soil at the riparian catchment scale were attempted to be simulated by coupling remotely sensed technology and simple processing models (Wang et al., 2010).

The Miyun reservoir is the terminal reservoir for the middle route of the SNWTP. It is the largest reservoir in North China and its design volume ranges within billion cubic 
meters. Since 1997, it has become the only surface drinking water supply for Beijing and exerts important impacts on the capital's social stability and economic development. Therefore, it is called the "life water" of the capital. After entering the 21 st century, the water volume dramatically decreased due to climatic change and human activities and more and more attention are focused on the water quality. As a crucial terminal reservoir, the water volume of the Miyun Reservoir will increase by 0.8 billion $\mathrm{m}^{3}$ due to water injected by the SNWT between 2015 and 2020. Furthermore, the water level will increase from currently $136 \mathrm{~m}$ to $150 \mathrm{~m}$ until 2020 (Yang et al., 2018a). As a result, the rapidly increasing water level will extensively inundate the riparian zone and may result in inevitable ecological risks for the water supply from this reservoir. Furthermore, the abilities of pollutant interception and nutrient degradation in the riparian zone may be weakened and the riparian zone may be rendered from a nutrient sink into a nutrient source (Bettez and Groffman, 2012; Schilling et al., 2006). Zhao et al. (2019) and Yang et al.(2018b) have reported that the plants in Miyun reservoir can effectively remove the $\mathrm{N}$ pollution, but the study about the $\mathrm{N}$ pollution removed by soil in Miyun reservoir under the SNWTP background has not been reported. Therefore, it is necessary to assess the variance of $\mathrm{N}$ emissions by soil induced by the SNWT in the Miyun reservoir. However, few studies have proposed a framework with which to estimate the effect of SNWT project on $\mathrm{N}$ removal by soil at the riparian catchment scale.

Consequently, the objective of this paper is to provide a useful framework with which to evaluate the SNWTP on N removal by soil in the Miyun riparian zone. Specifically, this study includes three steps: (1) coupling process-originated model and remotely sensed data to simulate the spatio-temporal varieties of $\mathrm{N}$ emissions by soil in the Miyun riparian zone between April and September in 2015; (2) dividing the riparian zone into four contour belts from low elevation to high elevation based on the Digital Elevation Model (DEM); (3) using a scenario setting method to estimate the influences of increasing water level induced by the SNWTP on N removal by soil at the Miyun riparian zone catchment scale. The simulated result is useful for the sustainable management of similar catchments than the Miyun riparian zone.

\section{Materials and methods}

\section{Study site}

This study was conducted in the riparian zone of the Miyun reservoir, which is located in the northeast of Beijing $\left(40^{\circ} 26^{\prime} \mathrm{N}-40^{\circ} 35^{\prime} \mathrm{N}, 116^{\circ} 47^{\prime} \mathrm{E}-117^{\circ} 05^{\prime} \mathrm{E}\right.$, Fig. 1). The riparian buffer in the Miyun reservoir mainly includes the region surrounded by the road that encircles the reservoir and other adjacent regions schemed by local authority. The Miyun reservoir was constructed in September 1960, and has a total storage capacity of 4.375 billion $\mathrm{m}^{3}$. The region belongs to the continental monsoon climate. The obvious climatic characteristic is an uneven distribution of precipitation and temperature over four seasons. About $70 \%$ of the precipitation falls between June and September (Yang et al., 2018a). In addition, the highest temperature during the year also occurs during this season. Figure 1 shows that the proportions of Calcareous cinnamon soil and Cambisol soil are the largest and smallest, accounting for about $50 \%$ and $0.28 \%$ of the study area, respectively. Soil types and soil property datasets in this study, including soil texture, soil nutrients content, bulk density, and $\mathrm{pH}$, were obtained based on the Second National Soil Survey and additional field investigation in the study region. 


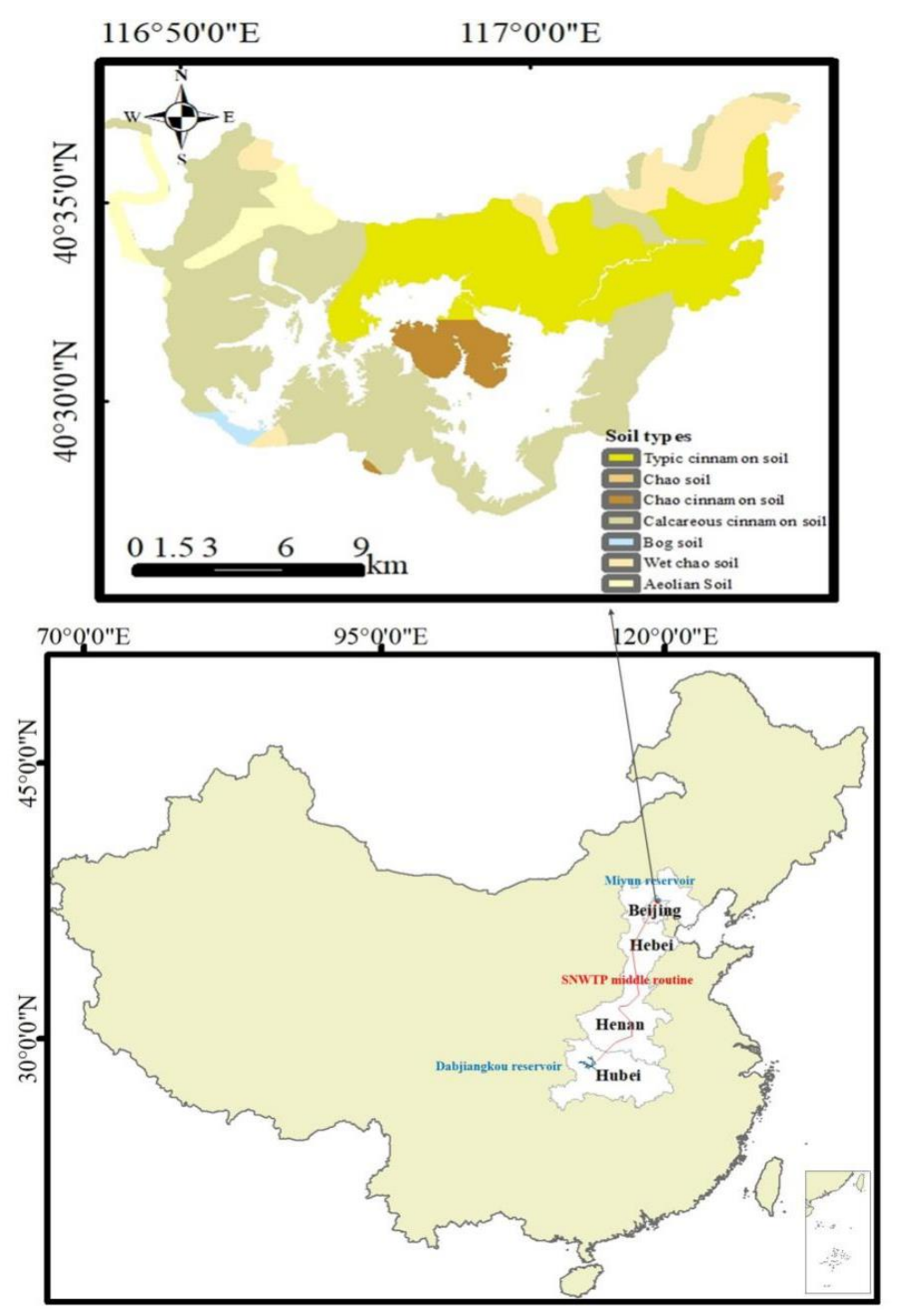

Figure 1. The study area distribution

\section{Framework method}

This section introduces the framework (Fig. 2) that was developed to assess the impacts of the SNWTP on N removal by soil. This framework integrates an ecological model assessment model and scenario setting method, and the specific parts are introduced in the following. Because the ecological model assessment model in Figure 2 has been successfully used in a Guanting Reservoir that has a similar geographical conditions and climate with Miyun Reservoir, the model parameters of the Guanting Reservoir are used to apply to the Miyun Reservoir simulation (Yang et al., $2018 b)$. Meanwhile, a field experiment in the nearby $\left(39^{\circ} 40.4^{\prime}-40^{\circ} 27.6^{\prime} \mathrm{N}, 116^{\circ} 28.2^{\prime}-\right.$ $117^{\circ} 1^{\prime}$ ') of Miyun Reservoir has been conducted (Geng et al., 2018). In this experiment, two typical drilling profiles were selected to determine the denitrification intensity value of the vadose zone at different sampling depths $(0-10 \mathrm{~m})$ and analyze the vertical spatial distribution of denitrification in the vadose zone. The experimental results show that the denitrification rate mainly in the soil layer of $0-0.25 \mathrm{~m}$. So, the soil layer depth between 0 and $25 \mathrm{~cm}$ was used to simulate the $\mathrm{N}$ emissions in this study. 


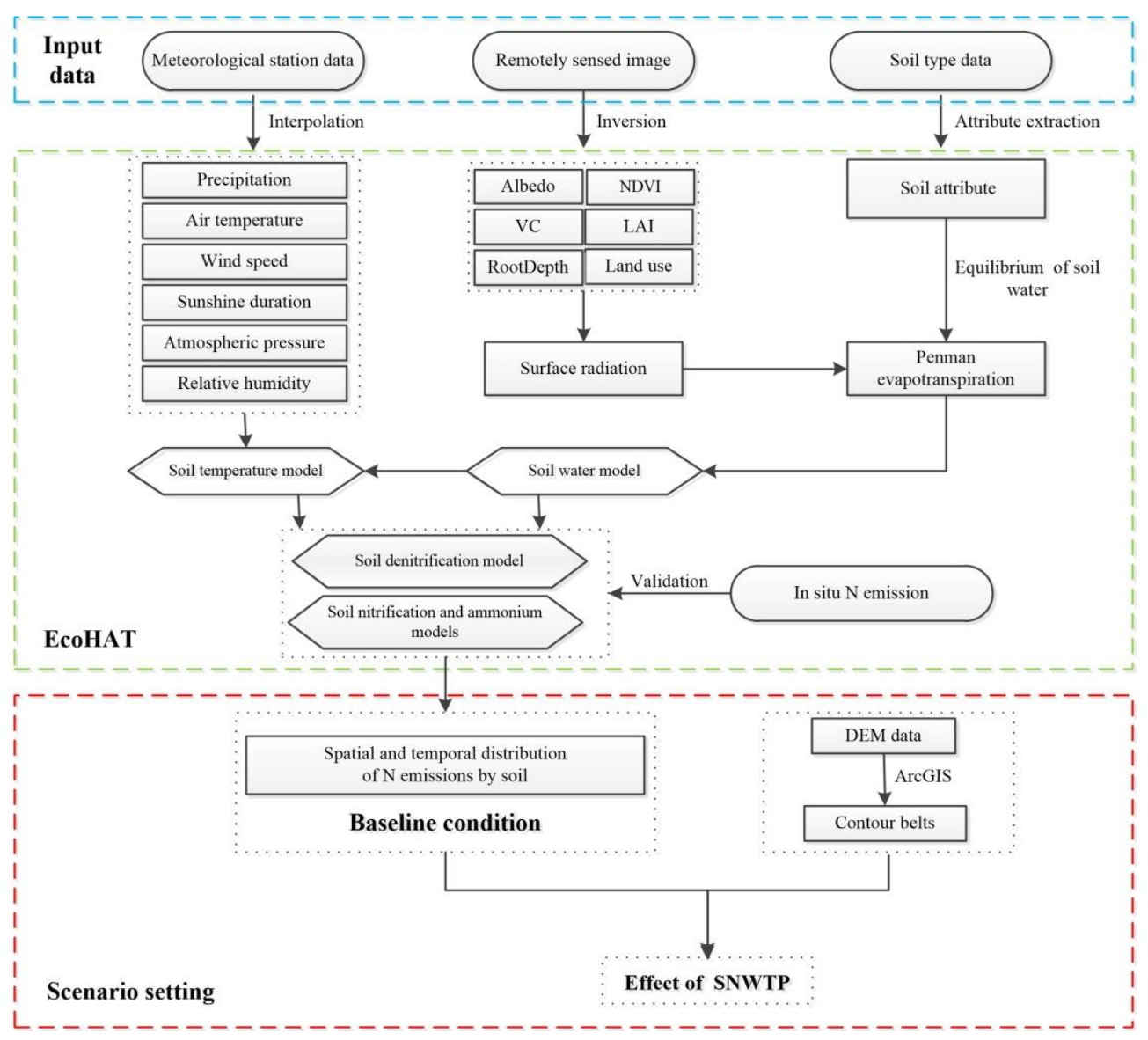

Figure 2. The framework method in this study. (VC is vegetation coverage, LAI is leaf area index)

\section{Model inputs}

(1) Remotely sensed data

The DEM data with 30-m resolution was obtained from the Advanced Spaceborne Thermal Emission and Reflection Radiometer (ASTER). Land use types (Fig. 3) were interpreted using the man-machine interactive method and the GF-1 multispectral data at a resolution of $8 \mathrm{~m}$. The types and proportions of land use in this riparian zone include forestland (28.72\%), grassland (24.52\%), farmland (13.45\%), bottomland $(6.27 \%)$, residential land $(3.17 \%)$, and water $(23.88 \%)$.

Considering the impacts of satellite observation errors and spatio-temporal resolutions, multispectral Landsat 8 OLI satellite images with $30-\mathrm{m}$ resolution between April and September 2015 were chosen. To eliminate the cloud interference with the spectral response to land surface targets, days 106, 138, 154, 186, 234, and 250 in 2015 for Landsat 8 OLI satellite data were chosen to invert the land surface parameters, e.g. VC, LAI, and land surface albedo. Additionally, to invert land surface parameters, a series of preprocessing steps such as radiometric, atmospheric, and geometric corrections were necessary. All of these preprocesses were operated using the ENVI 5.3 software. Finally, all image data mentioned above were re-projected into Albers with the World Geodetic System-84 datum and resampled into $30 \mathrm{~m} \times 30 \mathrm{~m}$ spatial resolutions. 


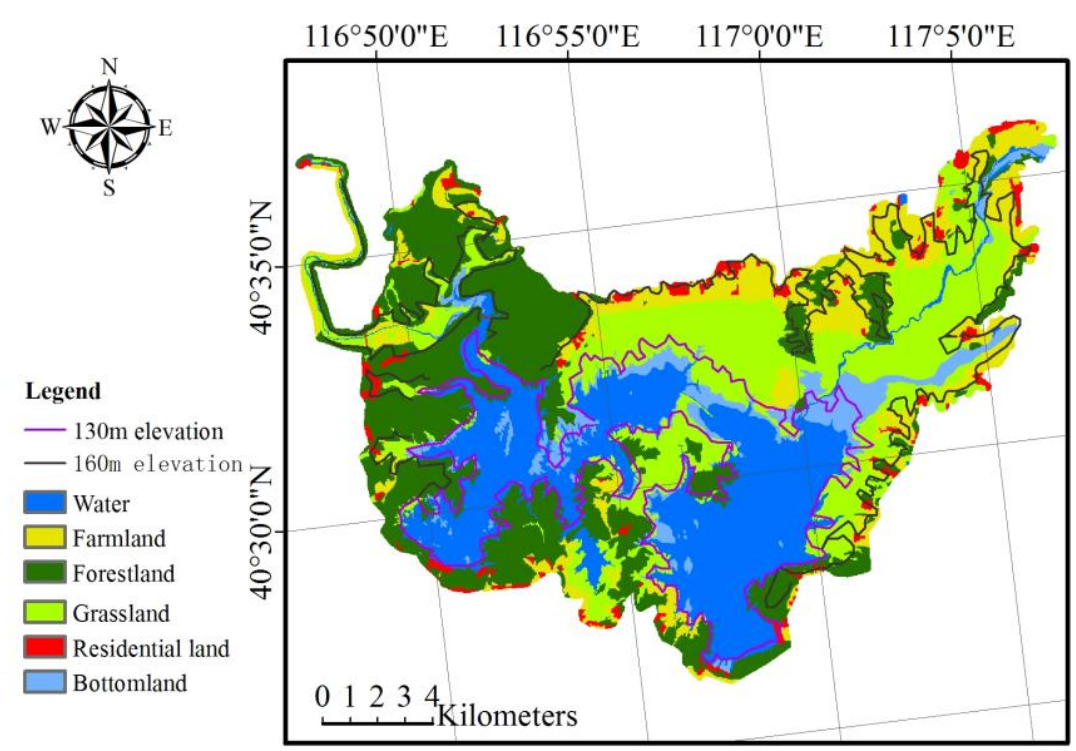

Figure 3. The land use distribution in Miyun riparian zone

\section{(2) Meteorological data}

The Beijing Meteorological Bureau and National Meteorological Information Center provided the daily observed rainfall data around the Miyun reservoir during the simulated period. Other daily observed climatic data from April to September in 2015 such as wind speed, air temperature, surface temperature, relative humidity, and sunshine duration were downloaded from the National Meteorological Information Center (http://data.cma.cn/site/index.html). The detailed information about the climatic data is listed in Table Al in the Appendix. All collected site records were generated as raster images using the Inverse Distance to a Power interpolation method using ArcGIS version 9.3.1.

\section{Model descriptions}

To simulate nitrogen emissions by the soil of the Miyun riparian zone, an Ecohydrological Assessment Tool (EcoHAT, Liu et al., 2009; Yang et al., 2011) was adopted in this study. EcoHAT was developed based on the mechanism of the ecohydrological processes in the Soil-Plant-Atmosphere Continuum (Dong et al., 2014). It was derived via multi-source data and can simulate hydrological processes, vegetation growth, and nutrient dynamics (Liu et al., 2009). The model used in this study mainly consists of three components: calculations of environmental factors i.e., soil temperature, soil moisture, and soil nitrogen; calculations of soil denitrification; calculations of soil nitrification and ammonia volatilization. Tables $A 2$ and $A 3$ (Appendix) show the main equations. In addition, model input parameters i.e., NDVI, LAI, and Albedo, were derived from Landsat 8 data via remotely sensed inversion. The detailed extraction processes of input parameters and part model principle have been introduced in Zhao et al. (2019) and Yang et al. (2018b). Additionally, Yang et al. (2018b) reported that the EcoHAT has been successfully applied to simulate the $\mathrm{N}$ emissions at a region that has similar geographical conditions and climate than the Miyun reservoir; therefore, experimental model parameters in Wang et al. (2010) were chosen for this study. 


\section{Estimation of SNWTP influences}

This section describes how to estimate the influences of SNWTP on nitrogen removal by soil in the riparian zone based on the simulated results of the EcoHAT model and the scenario setting method. Before estimating the impacts of the SNWTP, the Miyun riparian zone was first divided into four DEM-based contour belts using ArcGIS software. These four contour belts were respectively 130-140 m, 140-150 m, 150-160 m, and 160-170 m. Then, statistics about $\mathrm{N}$ emission of each contour were calculated based on the overlay of these four contour belts and the spatial distribution of N emissions by soil from April to September 2015, and for the simulated period. Finally, this study adopted a scenario setting method to suppose that the four contour belts in the Miyun riparian zone were submerged one by one from lower to higher elevations and gaseous $\mathrm{N}$ mission in every flooded soil belt was not included in the $\mathrm{N}$ removal by soil in the riparian zone.

\section{Model validation in situ}

Because the direct measurement of gaseous $\mathrm{N}$ emissions in the field is very difficult, a nitrogen mass conservation method was used to validate the gaseous $\mathrm{N}$ emissions by soil induced by denitrification, nitrification, and ammonia volatilization. In this method, the total $\mathrm{N}$ variances in situ are the sum of leaching $\mathrm{N}, \mathrm{N}$-uptake by vegetation, and gaseous $\mathrm{N}$ emissions. The following equation shows the nitrogen mass balance:

$$
T N_{s o}-T N_{s n}=N_{s e}+N_{p a}+N_{l e}
$$

where $T N_{s o}$ and $T N_{s n}$ are respectively the original total nitrogen content and total nitrogen content left in the soil $\left(\mathrm{mg} \mathrm{m}^{-2} \mathrm{~d}^{-1}\right), N_{s e}$ is the total gaseous $\mathrm{N}$ emissions $\left(\mathrm{mg} \mathrm{m}^{-2} \mathrm{~d}^{-1}\right), N_{p a}$ is the $\mathrm{N}$ uptake by plant $\left(\mathrm{mg} \mathrm{m}^{-2} \mathrm{~d}^{-1}\right), N_{\text {le }}$ is the leaching $\mathrm{N}\left(\mathrm{mg} \mathrm{m}^{-2} \mathrm{~d}^{-1}\right)$.

In this study, six sample data from three sample plots with $2 \mathrm{~m} \times 1 \mathrm{~m}$ in shrub $\left(116.848^{\circ} \mathrm{E}, 40.547^{\circ} \mathrm{N}\right)$, grassland $\left(116.947^{\circ} \mathrm{E}, 40.547^{\circ} \mathrm{N}\right)$, and farmland $\left(116.968^{\circ} \mathrm{E}\right.$, $40.559^{\circ} \mathrm{N}$ ) were measured during April and May 2015. Every sample plot was divided using an iron plate in the middle, the left and right parts were measured at the beginning and end of April and May, respectively. The $\mathrm{N}$ uptaken by plants was calculated using the biomass and $\mathrm{N}$ uptake ratio coefficients (Yang et al., 2018b).

\section{Results}

\section{Validation of $N$ emissions}

In this study, considering the precipitation distribution during the year (Fig. 4a), sample plots in April and May were used to validate the simulated results to minimize the influences of leaching $\mathrm{N}$ induced by precipitation. Figure $4 b$ shows the scatter plots between simulated and in situ gaseous $\mathrm{N}$ emission data. Moreover, the correlation coefficient was calculated using the software EXCEL 2010. As shown in Figure 4b, the coefficient of determination is $\mathrm{R} 2=0.77(\mathrm{P}<0.05)$, which implies that the model has a sound simulation effect. However, the validation result indicates that the observed data is smaller than the simulated data, the reasons may be related to the ignorance of $\mathrm{N}$ leaching and the scale effect between observed and simulated data. 

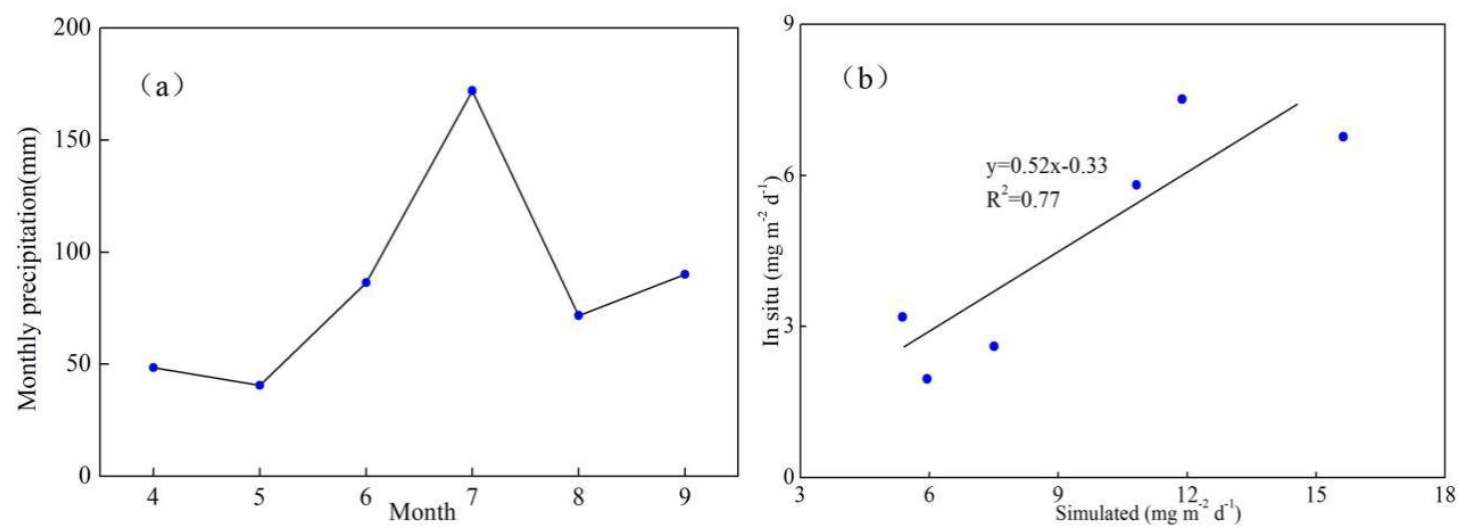

Figure 4. The monthly precipitation (a) and validation results of $N$ emissions (b)

\section{Spatio-temporal distribution of $N$ emissions by soil}

Figure 5 shows the spatial distributions of the simulated monthly gaseous $\mathrm{N}$ emission rate in the Miyun riparian zone from April to September in 2015. Figure 5 shows that the wetlands distributed near water are nitrogen enrichment regions and have relatively high $\mathrm{N}$ emissions by soil. In addition, it is worth mentioning that $\mathrm{N}$ emissions by soil in forestland in the north and west clearly exceed those of grassland and farmland in the northeast, especially from June to September. The reasons that explain this phenomenon are related to the soil water content. The soil type in the northeast of this study area is mainly typical cinnamon soil, and the soil type of forestland in this study area is mainly calcareous cinnamon soil (Fig. 3). The soil field capacity, soil saturated water content, and soil wilting water content $(0.31,0.45$, and 0.11$)$ in typical cinnamon soil are significantly lower than those $(0.28,0.44$, and 0.07$)$ of calcareous cinnamon soil based on the experimental analysis. Therefore, for the same rainfall, the calcareous cinnamon regions have higher soil water content, which can further increase the soil dis-anaerobic environment and increase the denitrification rate.

Figure 6 shows the spatial gaseous $\mathrm{N}$ emissions in the growing seasons of 2015 for the Miyun riparian zone. The yearly $\mathrm{N}$ emission distribution is similar to those of every month. After calculation, the emission distribution in the whole catchment is $871.97 \mathrm{t}$.

\section{Discrimination of $\mathrm{N}$ emission by different soil biochemical processes}

Based on the results of model simulation, the contributions of soil $\mathrm{N}$ emissions by denitrification, ammonia volatilization, and nitrification were estimated for the simulated period. Figure 6 shows that the three soil biochemical processes have similar temporal variation trends with a maximum in July and a minimum in April. In addition, Figure 7 also shows that the proportions of $\mathrm{N}$ emissions induced by the three biochemical processes in total gaseous $\mathrm{N}$ emissions are significantly different. The soil denitrification process dominated the soil $\mathrm{N}$ emissions in this study area; the $\mathrm{N}$ emissions ranged from $34.72 \mathrm{t}$ to $260.16 \mathrm{t}$ between April and September and the maximum of $260.16 \mathrm{t}$ of nitrogen occurred in July. In addition, the maximal values for soil nitrification and ammonia volatilization processes were $5.85 \mathrm{t}$ and $24.57 \mathrm{t}$ in July, respectively, and minimal values of $3.18 \mathrm{t}$ and $10.93 \mathrm{t}$ occurred in April. It is worth noting that soil denitrification rates showed dramatic fluctuations during the simulated period in comparison to the other two processes. 


\section{$N$ removal by soil in contour belts}

After statistical calculation, Figure Al (Appendix) shows that the $\mathrm{N}$ removal load of soil in the four contour belts were $380.38 \mathrm{t}, 342.79 \mathrm{t}, 302.72 \mathrm{t}$, and $981.59 \mathrm{t}$, respectively, from April to September. Furthermore, Figure Al shows the maximum N removals (107.77 t, $112.23 \mathrm{t}, 107.18 \mathrm{t}$, and $384.54 \mathrm{t})$ and the minimum $\mathrm{N}$ removals (26.35 t, $20.63 \mathrm{t}, 15.67 \mathrm{t}$, and $34.75 \mathrm{t}$ ) for July and April for the four contour belts. For each month, the $\mathrm{N}$ removal loads showed minor fluctuations from $130 \mathrm{~m}$ to $160 \mathrm{~m}$; where the elevations exceeded $160 \mathrm{~m}$, the $\mathrm{N}$ removal loads all steeply increased.
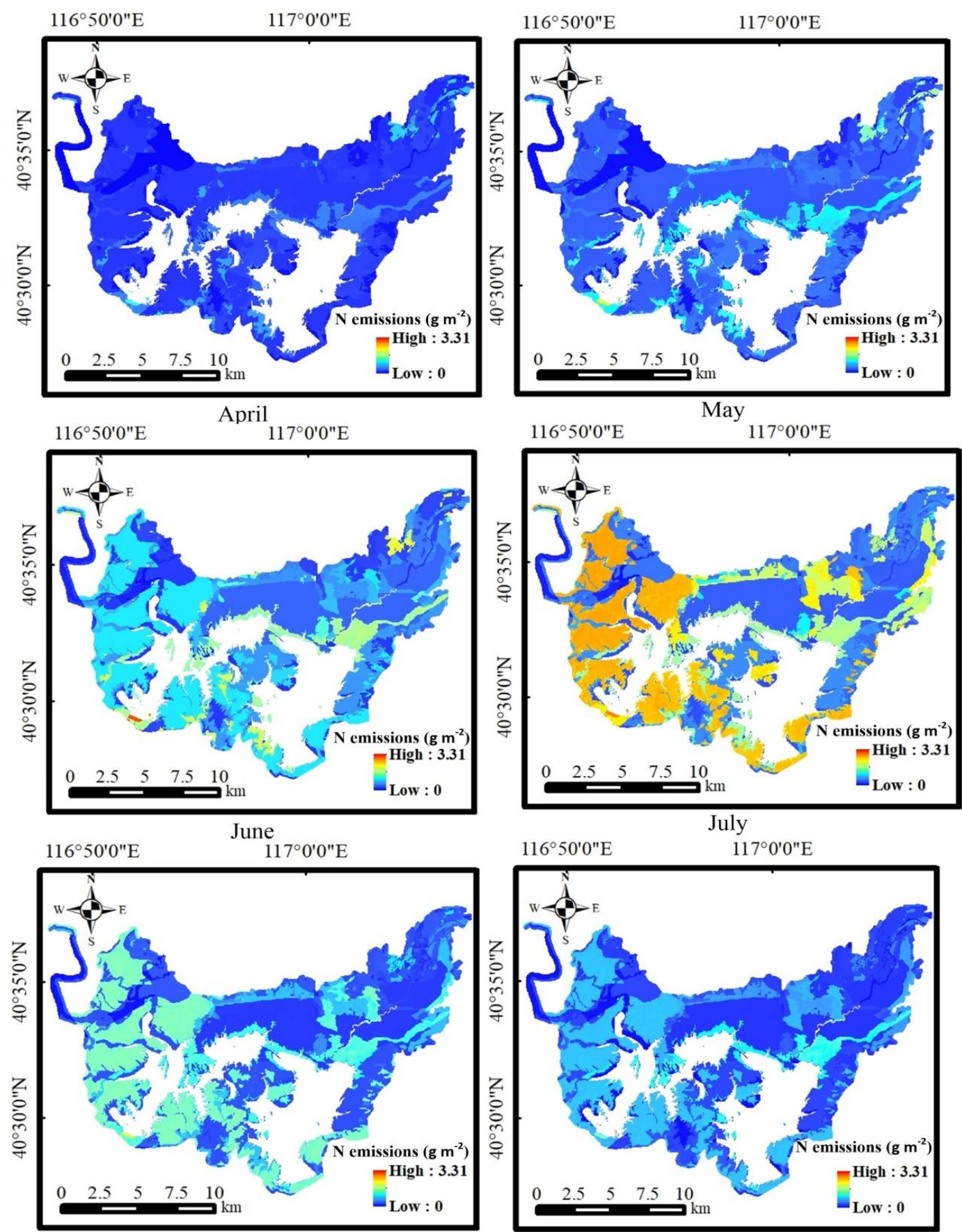

August

September

Figure 5. $N$ emissions rate by soil in study area from April to September 


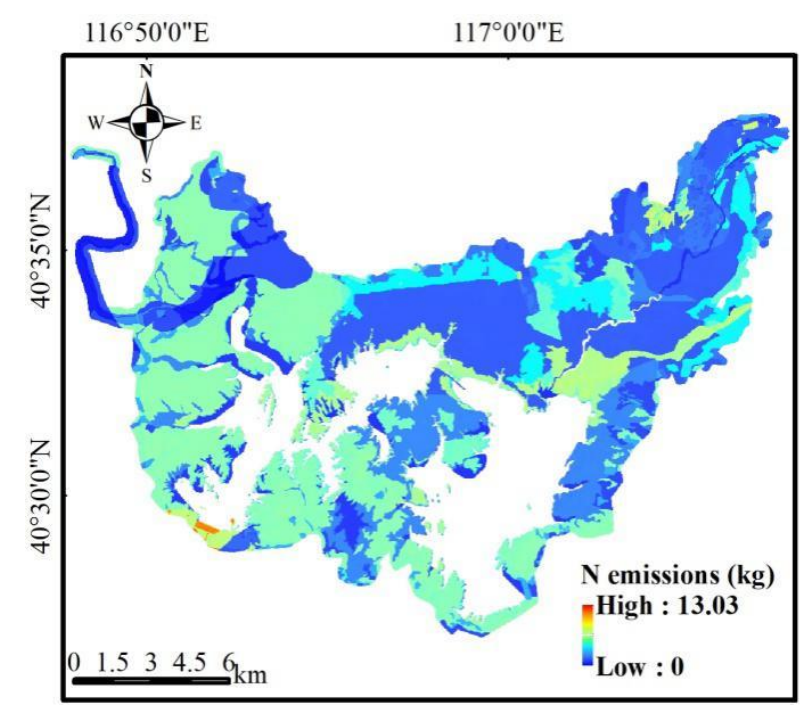

Figure 6. $N$ emissions amount by soil in study area in 2015

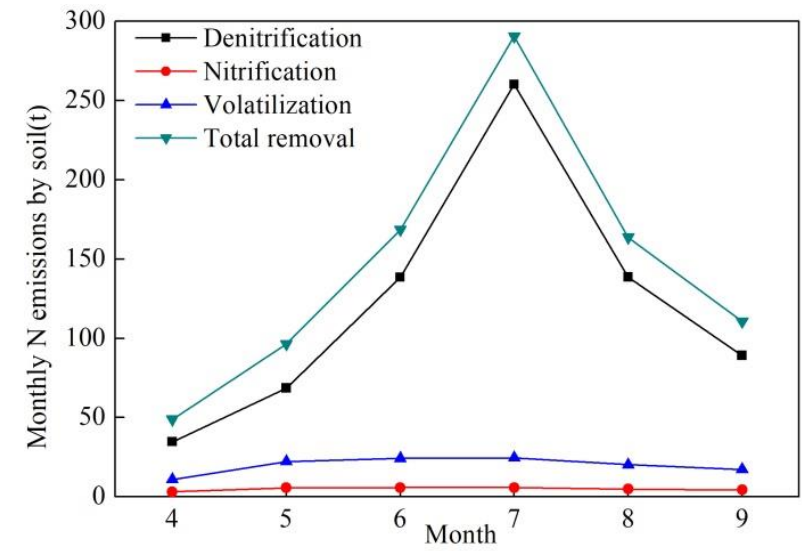

Figure 7. Monthly $N$ emissions for denitrification, nitrification and volatilization processes

\section{Influences of SNWTP on $N$ removal by soil in the Miyun riparian zone}

When the water transferred by the SNWTP was injected into the Miyun reservoir, the water level dramatically increased and extensively submerged the riparian zone. Figure A2 (Appendix) shows the $\mathrm{N}$ pollution by the riparian soil when SNWTP submerged the contour belts. Although the $\mathrm{N}$ pollution by soil in the riparian zone decreased for all months, the reduction extent was different for each month. When the water level increased to $150 \mathrm{~m}$, the riparian soil had about $50 \%$ of the original $\mathrm{N}$ absorption ability in April and May and had about 60\% between June and September. With the water level exceeding $160 \mathrm{~m}$, the riparian soil only had about $35 \%$ of the original $\mathrm{N}$ absorption ability in April and May and about 50\% from July to September. Furthermore, these results also imply that the submerged riparian zone may develop into a nutrient source from a nutrient sink (Schilling et al., 2006; Ye et al., 2012) when it became ineffective at removing nitrogen. 


\section{Discussion}

\section{Effects of land use types on gaseous $N$ emissions}

The $\mathrm{N}$ dynamics in riparian soil follow a close relationship to the plant distribution and types (Wu et al., 2016; Ye et al., 2015); therefore, the distribution of land use plays a key role in influencing the $\mathrm{N}$ emissions in the riparian zone (Bedard-Haughn et al., 2006; Wang et al., 2010). Table A4 (Appendix) shows the effect of land use type on the $\mathrm{N}$ emissions by soil, showing that the forestland has the most $\mathrm{N}$ emissions, accounting for $54.38 \%$ of the total gaseous $\mathrm{N}$ emissions. This is related to the forestland area distribution and soil moisture retention capacity. Furthermore, this study proves that denitrification is the most important way for the removal of $\mathrm{N}$ in three soil biochemical process, which is consistent with the results of previous studies (Bedard-Haughn et al., 2006; Kreiling et al., 2011; Ye et al., 2017; Wang et al., 2010). In this study, forestland showed the highest denitrification of the study period, accounting for $47.08 \%$ of total $\mathrm{N}$ emission; the grassland, farmland, and bottomland accounted for $11.44 \%, 12.79 \%$, and $12.11 \%$, respectively. In addition, the forestland and grassland dominated the nitrification and volatilization processes, accounting for $43.93 \%$ and $27.95 \%$ by soil nitrification and $44.06 \%$ and $27.66 \%$ by volatilization, respectively. The distribution of forest land on the higher elevation in this study has the most $\mathrm{N}$ emissions, which can partly be used to explain $\mathrm{N}$ removal by soil in contour belts where the elevations exceeded $160 \mathrm{~m}$.

\section{Adjusting riparian structure to improve the defense for $N$ pollution}

The results of this study showed that the increasing water level induced by the SNWTP can weaken $\mathrm{N}$ removal by soil in the riparian zone (Figs. Al and A2). A previous study reported that the vegetation restoration is an effective method for the remediation of degraded ecosystems by influencing soil properties in the riparian zone and by up-taking more nitrogen in the riparian (Zhang et al., 2010; Zhao et al., 2019). Consequently, it is necessary to illustrate the unit area $\mathrm{N}$ removal of the Miyun riparian zone. Figure A3 (Appendix) shows the monthly average $\mathrm{N}$ emission rate variations for different land use types between April and September. There are typical steep increases from April to July in all land use types. However, different land use categories have important effects on the $\mathrm{N}$ emission rates. The ranges of the monthly $\mathrm{N}$ emission rates for forestland and bottomland are from $0.15 \mathrm{~g} \mathrm{~m}^{-2}$ to $2.23 \mathrm{~g} \mathrm{~m}^{-2}$ and from $0.51 \mathrm{~g} \mathrm{~m}^{-2}$ to $1.45 \mathrm{~g} \mathrm{~m}^{-2}$, respectively, which exceed those of other types. The monthly soil emission rates for both forestland and bottomland are $0.94 \mathrm{~g} \mathrm{~m}^{-2}$ and $1.07 \mathrm{~g} \mathrm{~m}^{-2}$, respectively. The soil emission rates for other land use types were $0.32 \mathrm{~g} \mathrm{~m}^{-2}$ for grassland and $0.58 \mathrm{~g} \mathrm{~m}^{-2}$ for farmland.

According to previous studies (Zhang et al., 2010; Zhao et al., 2019) and the results shown in Figure A3, the adjustment of land use types can be used to increase the defense ability for $\mathrm{N}$ in the riparian zone. Specifically, the farmland and grassland distributed in the lower elevation area around the open reservoir water and the forestland distributed at higher elevation areas in this study. Therefore, this study suggests to change more grassland and farmland into forestland to effectively offset the impacts of SNWTP on the N removal by soil in the Miyun riparian. 


\section{Conclusions}

A number of studies reported that the soil in the riparian zones could significantly alleviate the water pollution risk by emitting gaseous N. The SNWTP is the largest inter-basin water transfer scheme in the world, and the Miyun reservoir is the terminal reservoir in the middle route of the SNWTP. With the injection of water since 2015, the riparian zone of the Miyun reservoir was extensively submerged. How to quantitatively assess the effects of increasing water induced by the SNWTP on the N removal in the Miyun riparian has become an important issue.

This study proposed a framework method that integrates the eco-hydrological model, remote sensing technology, and scenario setting to simulate the spatio-temporal varieties of $\mathrm{N}$ emissions and to assess influences of SNWTP on $\mathrm{N}$ removal by soil in the Miyun riparian zone. The scientificity of the simulated results has been validated by in situ survey data.

The results illustrate that wetlands near the water body are nitrogen enrichment regions and have relatively high $\mathrm{N}$ emissions by soil. In addition, the soil $\mathrm{N}$ emissions of forestland are higher than those of grassland and farmland, especially from June to September. Moreover, soil denitrification processes dominate soil $\mathrm{N}$ emission in this study area. After calculation, $\mathrm{N}$ emissions ranged from 48.83 t to $290.58 \mathrm{t}$ between April and September 2015 and the emission distribution in the whole catchment was $871.97 \mathrm{t}$.

When the water level increased to $150 \mathrm{~m}$, the riparian soil had about $50 \%$ of original defense $\mathrm{N}$ ability in April and May and had about $60 \%$ between June to September. However, the riparian soil had only about $35 \%$ of the original defense $\mathrm{N}$ ability in April and May and about 50\% from July to September with the water level exceeding $160 \mathrm{~m}$. This study demonstrates that changing farmland and grassland to forestland can effectively increase the amount of removed $\mathrm{N}$ in this riparian zone.

In summary, the results of this study are helpful for the sustainable management of similar catchment zones than the Miyun riparian zone. However, there are still many follow-up works to be further studied. In this study, the simulation does not consider the effect of groundwater level fluctuation on the removal of non-point pollutants in the Miyun riparian zone. In fact, the depth of groundwater in the riparian zone is shallow, and the water level fluctuates can greatly impact on the soil moisture, and then greatly affects the denitrification and nitrogen release process of the soil. Therefore, it is necessary to increase the simulation module of groundwater level in the future.

Acknowledgments. The China Postdoctoral Science Foundation (Grant No. 2016M591093), the National Key Research and Development Program of China (2017YFD0300400), the National Natural Science Foundation of China (Grant No. 41701517) and Major Science and Technology Program for Water Pollution Control and Treatment (Grant No.2018ZX07101005)provided the financial support for this study.

\section{REFERENCES}

[1] Barnett, J., Rogers, S., Webber, M., Finlayson, B., Wang, M. (2015): Sustainability: transfer project cannot meet China's water needs. - Nature 527(7578): 295-297.

[2] Bedard-Haughn, A., Matson, A. L., Pennock, D. J. (2006): Land use effects on gross nitrogen mineralization, nitrification, and $\mathrm{N}_{2} \mathrm{O}$ emissions in ephemeral wetlands. - Soil Biology \& Biochemistry 38(12): 3398-3406. 


$$
-15013 \text { - }
$$

[3] Bettez, N. D., Groffman, P. M. (2012): Denitrification potential in storm water control structures and natural riparian zones in an urban landscape. - Environmental Science \& Technology 46(20): 10909-10917.

[4] Blackburn, M., Ledesma, J. L. J., Näsholm, T., Laudon, H., Sponseller, R. A. (2017): Evaluating hillslope and riparian contributions to dissolved nitrogen $(\mathrm{N})$ export from a boreal forest atchment. - Journal of Geophysical Research-Biogeosciences 122: 324-339.

[5] Brovelli, A., Batlle-Aguilar, J., Barry, D. A. (2012): Analysis of carbon and nitrogen dynamics in riparian soils: model development. - Science of the Total Environment 429: 231-245.

[6] Butterbach-Bahl, K., Baggs, E. M., Dannenmann, M., Kiese, R., ZechmeisterBoltenstern, S. (2013): Nitrous oxide emissions from soils: how well do we understand the processes and their controls? - Philosophical Transactions of the Royal Society BBiological Sciences 368(1621): 20130122.

[7] Chavan, P. V., Dennett, K. E. (2008): Wetland simulation model for nitrogen, phosphorus, and sediments retention in constructed wetlands. - Water Air \& Soil Pollution 187(1-4): 109-118.

[8] Chen, Z. S., Wang, H. M., Qi, X. T. (2013): Pricing and water resource allocation scheme for the South-to-North Water Diversion Project in China. - Water Resources Management. 27(5): 1457-1472.

[9] de Sosa, L. L., Glanville, H. C., Marshall, M. R., Williams, A. P., Abadie, M., Clark, I. M., Blaud, A., Deng, K., Wang, J. G., Wang, J. Q. (2018): Treatments to control urban river pollution in water source city of south to north water diversion project. - Polish Journal of Environmental Studies 24(2): 501-504.

[10] Dong, G. T., Yang, S. T., Gao, Y. F., Bai, J., Wang, X. L., Zheng, D. H. (2014): Spatial evaluation of phosphorus retention in riparian zones using remote sensing data. Environmental Earth Sciences 72(5): 1643-1657.

[11] Erisman, J. W., Galloway, J. N., Seitzinger, S., Bleeker, A., Dise, N. B., Petrescu, A. M. R., Leach, A. M., de Vries, W. (2013): Consequences of human modification of the global nitrogen cycle. - Philosophical Transactions of the Royal Society B-Biological Sciences 368(1621): 20130116.

[12] Figueiredo, V., Enrich-Prast, A., Rütting, T. (2016): Soil organic matter content controls gross nitrogen dynamics and $\mathrm{N}_{2} \mathrm{O}$ production in riparian and upland boreal soil. European Journal of Soil Science 67(6): 782-791.

[13] Geng, H. Z., Huan, Y., Li, M. X., Zhang, Y., Cong, H., Xi, B. D. (2018): Vertical spatial distribution of denitrificatiion intensity in the vadose zone of typical sections of Chaobai River Alluvial Fan. - Environmental Science 39(11): 4972-4980 (Chinese and English abstract).

[14] Groffman, P. M., Butterbach-Bahl, K., Fulweiler, R. W., Gold, A. J., Morse, J. L., Stander, E. K., Tague, C., Tonitto, C., Vidon, P. (2009): Challenges to incorporating spatially and temporally explicit phenomena (hotspots and hot moments) in denitrification models. - Biogeochemistry 93(1-2): 49-77.

[15] Gu, W., Shao, D., Jiang, Y. (2012): Risk evaluation of water shortage in source area of middle route project for South-to-North Water Transfer in China. - Water Resources Management 26(12): 3479-3493.

[16] Hoang, L., van Griensven, A., Mynett, A. (2017): Enhancing the SWAT model for simulating denitrification in riparian zones at the river basin scale. - Environmental Modelling \& Software 93: 163-179.

[17] Islam, M. D. M., Sado, K. (2000): Development of flood hazard maps of Bangladesh using NOAA-AVHRR images with GIS. - Hydrological Sciences Journal 45(3): 337355.

[18] Jacinthe, P. A., Vidon, P. (2017): Hydro-geomorphic controls of greenhouse gas fluxes in riparian buffers of the White River watershed, IN (USA). - Geoderma 301: 30-41. 
[19] King, S. E., Osmond, D. L., Smith, J., Burchell, M. R., Dukes, M., Evans, R. O. (2016): Effects of riparian buffer vegetation and width: a 12-year longitudinal study. - Journal of Environmental Quality 45(4): 1243-1251.

[20] Kreiling, R. M., Richardson, W. B., Cavanaugh, J. C., Bartsch, L. A. (2011): Summernitrate uptake and denitrification in an upper Mississippi River backwater lake: the role of rooted aquatic vegetation. - Biogeochemistry 104: 309-324.

[21] Li, Y., Xiong, W., Zhang, W. L., Wang, C., Wang, P. F. (2016): Life cycle assessment of water supply alternatives in water-receiving areas of the South-to-North Water Diversion Project in China. - Water Research 89: 9-19.

[22] Li, Y. Y., Cui, Q., Li, C. H., Wang, X., Cai, Y. P., Cui, G. N., Yang, Z. F. (2017): An improved multi-objective optimization model for supporting reservoir operation of China's South-to-North Water Diversion Project. - Science of the Total Environment 575: 970-981.

[23] Lind, L. P. D., Audet, J., Tonderski, K., Hoffmann, C. C. (2013): Nitrate removal capacity and nitrous oxide production in soil profiles of nitrogen loaded riparian wetlands inferred by laboratory microcosms. - Soil Biology \& Biochemistry 60: 156-164.

[24] Liu, C., Zheng, H. (2002): South-to-North Water Tansfer schemes for China. International Journal of Water Resources Development 18: 453-471.

[25] Liu, C. M., Yang, S. T., Wen, Z. Q., Wang, X. L., Wang, Y. J., Li, Q., Sheng, H. R. (2009): Development of ecohydrological assessment tool and its application. - Science China-Technological Sciences 52(7): 1947-1957.

[26] Ma, F. B., Li, C. H., Wang, X., Yang, Z. F., Sun, C. C., Liang, P. Y. (2014): A Bayesian method for comprehensive water quality evaluation of the Danjiangkou Reservoir water source area, for the middle route of the South-to-North Water Diversion Project in China. - Front Earth Sci-Prc. 8(2): 242-250.

[27] Rojas-Oropeza, M., Dendooven, L., Garza-Avendano, L., Souza, V., Philippot, L., Cabirol, N. (2010): Effects of biosolids application on nitrogen dynamics and microbial structure in a saline-sodic soil of the former Lake Texcoco (Mexico). - Bioresource Technology 101(7): 2491-2498.

[28] Ryu, J., Cho, J., Kim, I. J., Mun, Y., Moon, J. P., Kim, N. W., Kim, S. J., Kong, D. S., Lim, K. J. (2011): Enhancement of SWAT-REMM to simulate reduction of total nitrogen with riparian buffer. - T Asabe. 54(5): 1791-1798.

[29] Schilling, K. E., Li, Z., Zhang, Y. K. (2006): Groundwater-surface water interaction in the riparian zone of an incised channel, Walnut Creek, Iowa. - Journal of Hydrology 327(1-2): 140-150.

[30] Seitzinger, S., Harrison, J. A., Bohlke, J. K., Bouwman, A. F., Lowrance, R., Peterson, B., Tobias, C., Van Drecht, G. (2006): Denitrification across landscapes and waterscapes: a synthesis. - Ecological Applications 16(-): 2064-2090.

[31] Shu, X., Zhang, K. R., Zhang, Q. F., Wang, W. B. (2017): Response of soil physicochemical properties to restoration approaches and submergence in the water level fluctuation zone of the Danjiangkou Reservoir, China. - Ecotoxicology And Environmental Safety 145: 119-125.

[32] Si, Z. H., Song, X. S., Wang, Y. H., Cao, X., Zhao, Y. F., Wang, B. D., Chen, Y., Arefe, A. (2018): Intensified heterotrophic denitrification in constructed wetlands using four solid carbon sources: denitrification efficiency and bacterial community structure. Bioresource Technology 267: 416-425.

[33] Tang, C. L., Yi, Y. J., Yang, Z. F. (2014): Water pollution risk simulation and prediction in the main canal of the South-to-North Water Transfer Project. - Journal of Hydrology 519: 2111-2120.

[34] Vymazal, J. (2007): Removal of nutrients in various types of constructed wetlands. Science of the Total Environment 380(1-3): 48-65.

[35] Wang, G. Q., Ouyang, Q., Zhang, Y. D., Wei, J. H., Ren, Z. Y. (2009): World' Water Diversion Project. - Publishing Science Press, Beijing. 
[36] Wang, X., Mannaerts, C. M., Yang, S., Gao, Y., Zheng, D. (2010): Evaluation of soil nitrogen emissions from riparian zones coupling simple process-oriented models with remote sensing data. - Science of the Total Environment 408(16): 3310-3318.

[37] Wei, J. B., Feng, H., Cheng, Q. G., Gao, S. Q., Liu, H. Y. (2017): Denitrification potential of riparian soils in relation to multiscale spatial environmental factors: a case study of a typical watershed, China. - Environmental Monitoring and Assessment 189(2): 85.

[38] Wu, H. L., Xu, K. Q., He, X. J., Wang, X. Z. (2016): Removal of nitrogen by three plant species in hydroponic culture: plant uptake and microbial degradation. - Water Air Soil Pollution 227(9): 324.

[39] Yang, Q., Xie, P., Shen, H., Xu, J., Wang, P. L., Zhang, B. (2012): A novel flushing strategy for diatom bloom prevention in the lower-middle Hanjiang River. - Water Research 46(8): 2525-2534.

[40] Yang, S. T., Dong, G. T., Zheng, D. H., Xiao, H. L., Gao, Y. F., Lang, Y. (2011): Coupling Xinanjiang model and SWAT to simulate agricultural non-point source pollution in Songtao watershed of Hainan, China. - Ecological Modelling 222(20-22): 3701-3717.

[41] Yang, S. T., Bai, J., Zhao, C. S., Lou, H. Z., Zhang, C. B., Guan, Y. B., Zhang, Y. C., Wang, Z. W., Yu, X. Y. (2018a): The assessment of the changes of biomass and riparian buffer width in the terminal reservoir under the impact of the South-to-North Water Diversion Project in China. - Ecological Indictor 85: 932-943.

[42] Yang, S. T., Bai, J., Zhao, C. S., Lou, H. Z., Wang, Z. W., Guan, Y. B., Zhang, Y. C., Zhang, C. B., Yu, X. Y. (2018b): Decline of N and P uptake in the inner protection zone of a terminal reservoir during inter-basin water transfers. - Water 10: 178. DOI: 10.3390/w10020178.

[43] Yang, W. H., Liu, Y. B., Ou, C. P., Gabor, S. (2016): Examining water quality effects of riparian wetland loss and restoration scenarios in a southern Ontario watershed. - Journal of Environmental Management 174: 26-34.

[44] Ye, C., Cheng, X. L., Zhang, Y. L., Wang, Z. X., Zhang, Q. F. (2012): Soil nitrogen dynamics following short-term revegetation in the water level fluctuation zone of the Three Gorges Reservoir, China. - Ecological Engineering 38(1): 37-44.

[45] Ye, C., Cheng, X. L., Zhang, Q. F. (2014): Recovery approach affects soil quality in the water level fluctuation zone of the Three Gorges Reservoir, China: implications for revegetation. - Environmental Science And Pollution Research 21(3): 2018-2031.

[46] Ye, C., Cheng, X. L., Liu, W. Z., Zhang, Q. F. (2015): Revegetation impacts soil nitrogen dynamics in the water level fluctuation zone of the Three Gorges Reservoir, China. Science of the Total Environment 517: 76-85.

[47] Ye, C., Chen, C. G., Du, M., Liu, W. Z., Zhang, Q. F. (2017): Revegetation affects soil denitrifying communities in a riparian ecotone. - Ecological Engineering 103: 256-263.

[48] Zeng, Q., Qin, L., Li, X. (2015): The potential impact of an inter-basin water transfer project on nutrients (nitrogen and phosphorous) and chlorophyll a of the receiving water system. - Science of the Total Environment 536: 675-686.

[49] Zhang, J., Meng, F., Lu, Y., Jing, Y., Zhang, H., Zhang, B. (2008): Ecological assessment of lakeshore wetland rehabilitation on eastern route of South-to-North Water Transfer Project. - Frontiers of Environmental Science \& Engineering China 2(3): 306-310.

[50] Zhang, K., Dang, H., Tan, S., Wang, Z., Zhang, Q. (2010): Vegetation community and soil characteristics of abandoned agricultural land and pine plantation in the Qinling Mountains, China. - Forest Ecology and Management 259(10): 2036-2047.

[51] Zhang, M. L., Hu, L. T., Yao, L. L., Yin, W. J. (2018): Numerical studies on the influences of the South-to-North Water Transfer Project on groundwater level changes in the Beijing Plain, China. - Hydrological Process 32(12): 1858-1873. 


$$
-15016 \text { - }
$$

[52] Zhang, Q. (2009): The South-to-North water transfer project of China: environmental implications and monitoring strategy 1. - Journal of the American Water Resources Association 45(5): 1238-1247.

[53] Zhao, H. G., Yang, S. T., Huang, Y. C. (2018): Utilizing the MODIS-derived leaf area index to investigate the impact of vegetation processes on hydrological simulation of macroscale catchment. - Environmental Earth Sciences 77(4): 11. DOI: 10.1007/s12665017-7187-3.

[54] Zhao, H. G., Huang, Y. C., You, S. C., Wu, Y. F., Zheng, F. X. (2019): A framework for assessing the effects of afforestation and South-to-North Water Transfer on nitrogen and phosphorus uptake by plants in a critical riparian zone. - Science of the Total Environment 651: 942-952.

[55] Zhong, R. H., Hu, J. M., Bao, Y. H., Wang, F., He, X. B. (2018): Soil nutrients in relation to vertical roots distribution in the riparian zone of Three Gorges Reservoir, China. Journal of Mountain Science 15(7): 1498-1509.

[56] Zhuang, W. (2016): Eco-environmental impact of inter-basin water transfer projects: a review. - Environmental Science and Pollution Research International 23(13): 1286712879.

\section{APPENDIX}

Table A1. Detailed information of observed meteorological stations

\begin{tabular}{c|c|c|c}
\hline ID & Longitude & Latitude & Resources \\
\hline 1 & 116.81 & 40.56 & \\
2 & 116.85 & 40.47 & \\
3 & 116.85 & 40.60 & \\
4 & 116.87 & 40.62 & \\
5 & 116.93 & 40.42 & Beijing Meteorological \\
6 & 116.97 & 40.57 & Bureau \\
7 & 117.04 & 40.58 & \\
8 & 117.12 & 40.61 & \\
9 & 117.13 & 40.54 & \\
10 & 116.79 & 40.62 & \\
11 & 117.10 & 40.44 & \\
\hline 12 & 116.38 & 41.12 & Information Center \\
13 & 116.52 & 40.23 & \\
14 & 117.55 & 40.58 & \\
15 & 117.57 & 40.12 & \\
\hline
\end{tabular}

Table A2. Main equations in the denitrification process

\begin{tabular}{c|c|c}
\hline No. & Functions & Equations \\
\hline 1 & Potential denitrification rate & $D_{a}=D_{P} f_{N} f_{S} f_{T} f_{P H}$ \\
\hline 2 & Actual denitrification rate & $D_{P}=\frac{4}{5} \frac{\alpha_{o m}}{365} C \frac{14}{12} 10^{6}$ \\
\hline 3 & Soil nitrate reduction & $f_{N}=\min \left[1, \frac{N}{N_{c r i t}}\right]$ \\
\hline
\end{tabular}




\begin{tabular}{|c|c|c|}
\hline 4 & Soil temperature reduction & $f_{T}= \begin{cases}0 & T_{s} \leq 0 \\
Q_{10}^{0.1\left(T_{s}-T_{r}\right)} & 0<T_{s}<T_{r} \\
1 & T_{r} \leq T_{s}\end{cases}$ \\
\hline 5 & Saturation degree & $S=S_{w} /\left(1-\rho_{d} / \rho_{s}\right)$ \\
\hline 6 & Soil water content reduction & $f_{s}=\left\{\begin{array}{lc}0 & S<S_{t} \\
\left(\frac{S-S_{t}}{S_{m}-S_{t}}\right)^{w} & S_{t} \leq S \leq S_{m} \\
1 & S=S_{m}\end{array}\right.$ \\
\hline 7 & Soil PH reduction & $f_{P H}= \begin{cases}0 & P H \leq 3.5 \\
(P H-3.5) / 3 & 3.5<P H<6.5 \\
1 & P H \geq 6.5\end{cases}$ \\
\hline
\end{tabular}

$D_{a}$ is actual denitrification rate $\left(\mathrm{mg} \mathrm{N} \mathrm{kg}^{-1} \mathrm{~d}^{-1}\right) ; D_{p}$ is the potential denitrification rate $\left(\mathrm{mg} \mathrm{N} \mathrm{kg}^{-1}\right.$ $\left.\mathrm{d}^{-1}\right) ; f_{N}, f_{S}, f_{T}$ and $F_{P H}$ respectively represents a dimensionless reduction function for soil nitrate content, soil water content $([0,1])$, soil temperature soil $\mathrm{pH} ; \alpha_{o m}$ is the yearly decay rate of organic matter $([0,1]) ; C$ is the soil carbon content $\left(\mathrm{g} \mathrm{C} \mathrm{g}^{-1}\right) ; N$ is the soil nitrate- $\mathrm{N}$ content $\left(\mathrm{mg} \mathrm{N} \mathrm{kg}^{-1}\right) ; N_{\text {crit }}$ is the critical soil nitrate- $\mathrm{N}$ content below which denitrification is assumed to be limited; $T_{s}$ and $T_{r}$ are the soil temperature $\left({ }^{\circ} \mathrm{C}\right)$ and reference temperature $\left({ }^{\circ} \mathrm{C}\right) ; Q_{10}$ is an increase factor in $f_{T}$ at an increase in $T$ of $10^{\circ} \mathrm{C} ; S$ is the dimensionless degree of saturation; $S_{m}$ and $S_{t}$ are $S$ above which $f_{S}=1$ and $f_{S}=0$ respectively; $S W$ is the soil water content $\left(\mathrm{cm}^{3} \mathrm{~cm}^{-3}\right) ; \rho_{d}$ and $p_{s}$ are the dry bulk density $(\mathrm{g}$ $\left.\mathrm{cm}^{-3}\right)$ and solids density $\left(\mathrm{g} \mathrm{cm}^{-3}\right) ; w$ is a measure for the steepness of the curve $\left(S-S_{t}\right) /\left(S_{m}-S_{t}\right)$

Table A3. Main equations in the nitrification and volatilization processes

\begin{tabular}{|c|c|c|}
\hline No. & Functions & Equations \\
\hline 1 & $\begin{array}{l}\text { NO from } \\
\text { nitrification }\end{array}$ & $N O=0.0025 \cdot N_{n i t / 1 y} \cdot \eta_{t e m, 1 y}$ \\
\hline 2 & $\begin{array}{l}\text { N removed from } \\
\text { NH4 + pool by } \\
\text { nitrification }\end{array}$ & $N_{n i t, 1 y}=\left[1-\exp \left(-\eta_{n i t, 1 y}\right)\right] /\left[1-\exp \left(-\eta_{n i t, 1 y}\right)+1-\exp \left(-\eta_{v o l, 1 y}\right)\right] \times N_{n i t / v o l, 1 y}$ \\
\hline 3 & $\begin{array}{l}\mathrm{N} \text { production from } \\
\mathrm{NH} 4+\text { to } \mathrm{NH} 3\end{array}$ & $N_{v o l, 1 y}=\left[1-\exp \left(-\eta_{v o l, 1 y}\right)\right] /\left[1-\exp \left(-\eta_{n i t, 1 y}\right)+1-\exp \left(-\eta_{v o l, 1 y}\right)\right] \times N_{n i t / v o l, 1 y}$ \\
\hline 4 & $\begin{array}{l}\mathrm{NH} 4+\text { converted } \\
\text { from nitrification } \\
\text { and volatilization }\end{array}$ & $N_{n i t / v o l, 1 y}=N H_{4,1 y}^{+} \times\left[1-\exp \left(-\eta_{n i t, 1 y}-\eta_{v o l, 1 y}\right)\right]$ \\
\hline 5 & $\begin{array}{l}\text { Nitrification } \\
\text { regulator }\end{array}$ & $\eta_{n i t, 1 y}=\eta_{t e m, 1 y} \times \eta_{s w, 1 y}$ \\
\hline 6 & $\begin{array}{l}\text { Volatilization } \\
\text { regulator }\end{array}$ & $\eta_{v o l, 1 y}=\eta_{t e m, 1 y} \times \eta_{m i d z, 1 y} \times \eta_{c e c, 1 y}$ \\
\hline 7 & $\begin{array}{l}\text { Volatilization depth } \\
\text { factor }\end{array}$ & $\eta_{m i d z l y}=1-\frac{Z_{m i d, I y}}{Z_{m i d, I y}+\exp \left[4.706-0.0305 \times Z_{m i d, I y}\right]}$ \\
\hline
\end{tabular}

$\eta_{t e m, l y}$ and $\eta_{s w, l y}$ is the nitrification/volatilization temperature and soil moisture factors; $\eta_{\text {midz,ly }}$ is the volatilization depth factor; $\eta_{c e c, l y}$ is cation exchange factor, $\eta_{c e c, l y}=0.15 ; Z_{m i d, l y}$ is the depth from the soil surface to the middle of the layer $(\mathrm{mm})$; and $\eta_{c e c}$ is the volatilization cation exchange factor. $N_{\text {nit } / \text { vol,ly }}$ is the amount of ammonium converted via nitrification and volatilization in layer $l y$ $\left(\mathrm{kg} \mathrm{N} \mathrm{m}^{-2}\right)$; $\mathrm{NH}_{4}{ }^{+}, y$ is the amount of ammonium in layer $l y\left(\mathrm{~kg} \mathrm{~N} \mathrm{~m}^{-2}\right) ; \eta_{n i t, l y}$ and $\eta_{v o l, l y}$ is the nitrification and volatilization regulators; $N_{\text {nit,ly }}$ is the amount of nitrogen removed from the ammonium pool by nitrification $\left(\mathrm{kg} \mathrm{N} \mathrm{m}^{-2}\right.$ ); and $\mathrm{N}_{\mathrm{vol}, \mathrm{ly}}$ is the amount of nitrogen removed from the ammonium pool by volatilization $\left(\mathrm{kg} \mathrm{N} \mathrm{m}^{-2}\right)$ 


$$
-15018 \text { - }
$$

Table A4. Gaseous N emissions by the different soil biochemical processes in different land use ( $t$ )

\begin{tabular}{c|c|c|c|c}
\hline Land use & Denitrification & Nitrification & Volatilization & Total removal \\
\hline Forestland & 397.84 & 12.37 & 49.32 & 459.53 \\
Farmland & 108.05 & 5.38 & 21.33 & 134.76 \\
Bottomland & 102.37 & 2.54 & 10.34 & 115.25 \\
Grassland & 96.62 & 7.87 & 30.96 & 135.45 \\
\hline
\end{tabular}

Figure A1. The distributions of $N$ removal by soil in Miyun riparian zone

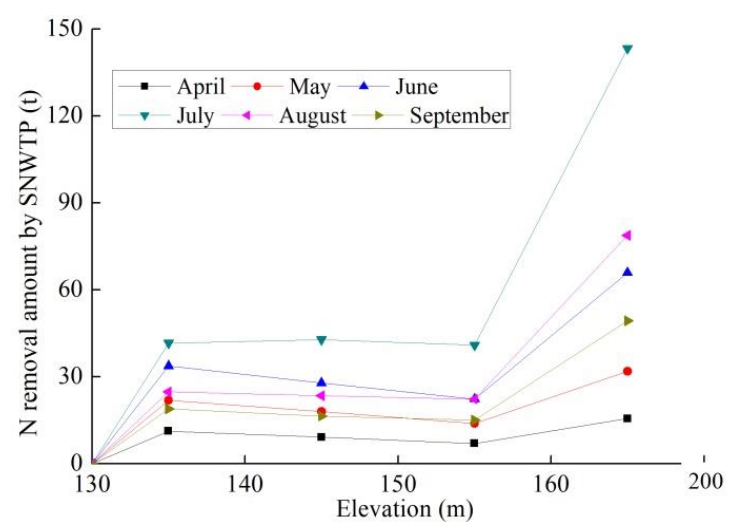

Figure A2. The defense for N pollution by riparian soil after SNWTP in Miyun riparian zone

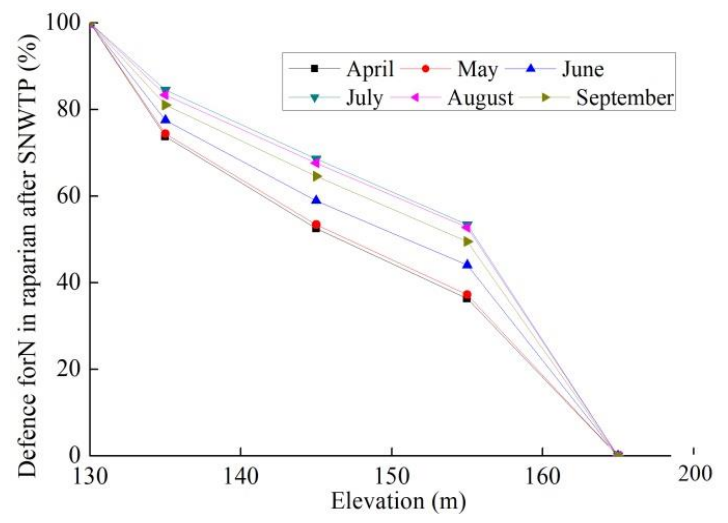

Figure A3. $N$ emissions rates by soil from April to September in different land use

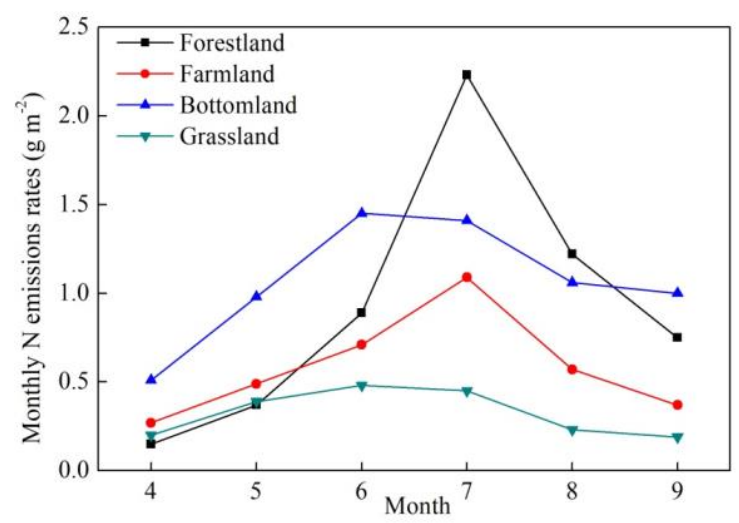

